\title{
Knowledge and Practice of Essential Newborn Care and Associated Factors among Nurses and Midwives Working at Health Centers in Jimma Zone, Ethiopia, 2016
}

\author{
Bayisa Bereka Negussie ${ }^{1 *}$, Fikadu Balcha Hailu ${ }^{2}$ and Asrat Demissie Megenta ${ }^{3}$ \\ ${ }^{1}$ College of Public Health and Medical Sciences, Jimma University, Ethiopia \\ ${ }^{2}$ Institute of Health, School of Nursing and Midwifery, Jimma University, Ethiopia \\ ${ }^{3}$ College of Health Science, School of Nursing, Addis Ababa University, Ethiopia
}

"Corresponding author: Bayisa Bereka Negussie, Neonatal Nursing Program Coordinator, Jimma University College of Public Health and Medical Sciences, Nursing and Midwifery, Jimma, Oromia, Ethiopia, Tel: +251917238905; E-mail: baayyisaab@gmail.com

Received date: December 17, 2017; Accepted date: February 05, 2018; Published date: February 13, 2018

Copyright: (c) 2018 Negussie BB, et al. This is an open-access article distributed under the terms of the Creative Commons Attribution License, which permits unrestricted use, distribution, and reproduction in any medium, provided the original author and source are credited

\section{Abstract}

Background: In Ethiopia, institutionalization of deliveries are happening at a fast pace. Assessing the knowledge and practice of midwives and nurses in these institutions is a priority in this current scenario. The initial adaptations by the baby at the time of birth should be facilitated by the midwives by giving essential newborn care. Therefore, this study is aimed to identify knowledge and performance gap on essential newborn care.

Objective: The objective of this study was to assess knowledge and practice of essential newborn care and associated factors.

Methods: Facility based cross-sectional design was conducted. Simple random sampling method was used to select the estimated 279 study participants from those who provide delivery and neonatal care. Self-administer questionnaires was distributed to participants to collect data and facilitated by data collectors. Data was entered to EpiData Manager and exported to statistical package for social sciences version 20 and analyzed. Finally, the result was illustrated in the form of text and tables.

Results: The mean knowledge score of study participants was 23.27 . The study revealed that $52.2 \%$ and $47.8 \%$ of the respondents had good and poor knowledge respectively. The mean score of practice was 32.82 and $51.1 \%$ and $48.9 \%$ of the respondents had good and poor level of practice respectively. Field of study, educational level, interest to work in delivery room, in-service training was significantly associated with level of essential newborn care practice.

Conclusion and recommendation: The study population had poor knowledge and practice on some components of essential newborn care. Level of education, interest, in-service training and level of knowledge were found to be independent predictors of practice. Hence, strengthening of in-service training, priority should be given for those trained to give delivery and newborn care service, and incorporation of all components of essential newborn care in curriculum was recommended.

Keywords: Knowledge; Practice; Essential newborn care; Midwives; Nurses

\section{Background}

The transition to extra uterine and initial adaptations are crucial to the baby's subsequent wellbeing and should be understood and facilitated by the health care providers at the time of birth and after birth by giving essential newborn care (ENC) [1]. The care health workers provide at time of birth is critical in helping to prevent complications and ensuring survival [2]. Skilled care during labour and childbirth with prompt management of complications alone can prevent about $50 \%$ of newborn mortality and $45 \%$ of intra-partum stillbirths. Combined with adequate newborn care in the postnatal period, $75 \%$ of current newborn deaths can be prevented [3]. Therefore, WHO recommends ENC; is a comprehensive strategy designed to improve the health of newborns through interventions before conception, during pregnancy, at and soon after birth and in the postnatal period $[4,5]$. The ENC Protocol is a series of time bound and chronologically-ordered that a baby receives at birth and it has standardized effective procedural steps: dry and stimulate, evaluate breathing, cord care, keep the newborn warm (Prevent hypothermia), initiate breastfeeding within the first one hour, administer eye drops/eye ointment, administer vitamin $\mathrm{k}$ intramuscularly, place the newborn's identification bands, weigh the newborn when it is stable and warm, record all observations and treatment provided, delay bathing of the baby for $24 \mathrm{~h}$ after birth [6,7].

Newborns are most vulnerable during the first hours and days of life, yet this critical window of opportunity is being missed. While evidence shows that initiating breastfeeding within one hour of birth reduces the baby's risk of death by $44 \%$, recent data show that less than half of newborn babies worldwide receive the benefits of immediate breastfeeding. Great efforts have been made to improve neonatal death 
around the world over the past four decades, yet achievements have not been as expected [8]. As many as two-thirds of neonatal deaths could be saved with ENC. Simple interventions to improve in health facilities have demonstrated up to $47 \%$ reduction in newborn mortality in Tanzania [9]. Unless newborn receives appropriate basic care, they quickly fall sick and too often they die [10]. Ethiopia is one of the ten countries with the highest number of neonatal deaths globally and neonatal mortality has remained stable at around 37 deaths per 1000 live births in recent years $[10,11]$ and in Jimma there was high status of neonatal mortality and immediate neonatal care practices were identified as one of the determinant factors [12].

Promotion of ENC is one strategy for improving newborn health outcomes [13]. This requires health systems that provide continuity of care starting from the beginning of pregnancy (and even before) and continuing through professional skilled care at birth into the postnatal period. But, the standardized procedure for providing ENC is not commonly practiced [14]. Knowledge is one of the crucial aspects of health systems to adherence to ENC practices. But, in Ethiopia hospitals health workers' mean knowledge score for immediate newborn care was relatively low and there was performance gap on immediate ENC provided until the first hour after birth [15].

In addition to this gap, although midwives and nurses are providing primary care to women during pregnancy, labor, ENC care and the postpartum period in almost all health centers, still there is no study about knowledge and practice of ENC among midwives and nurses working at health centers in Jimma zone. Therefore, the main purpose of this study is to identify whether there is knowledge and performance gap on ENC among nurses and midwives.

\section{Methods}

Facility based cross-sectional study design was conducted in 68 health centers found in ten Districts of Jimma zone from March 9 to April 8, 2016. A total of 279 participants were participated in the study which was selected by simple random sampling from those who were actively providing delivery care after proportional allocation was made for each Districts and health centers based on the number of nurses of each health center in the selected Districts as sampling frame. A single population proportion formula was used to estimate the sample size. There was no study conducted in Jimma area on the topic. To estimate the desired sample size, the following assumptions were made: proportion of knowledge and practice of study participants on ENC was taken as $50 \%(\mathrm{p}=0.5)$, level of significance was considered to be $5 \%$ $(\alpha=0.05), 95 \%$ confidence level $(Z \alpha / 2=1.96)$ and margin of error to be tolerated $5 \%(\mathrm{~d}=0.05)$. Because of the source population is less than 10,000 ; sample size correction was made to estimate the final sample size and $10 \%$ of the sample size added for non-response rate that made the final sample size of 279 .

All qualified diploma and degree nurses and midwives recruited by government who provide delivery care services at selected health centers were included whereas those who did not provide delivery care services within the last six month prior to data collection to the time of data collection were excluded.

Data was collected by distributing self-administered structured questionnaires that adopted from published articles and further modification was done based on the Ethiopian Federal Ministry of health newborn care training Participants manual [7]. The questionnaire had both closed and open ended questions and participants were completed the necessary information by themselves.
Data collectors facilitated data collection process and helped the participants in case if they had any questions on the items of tool. Data collectors waited for each respondent to complete their questionnaire and immediately retrieved after they completed. After standardized study tool was adopted, tool was checked for validity by three professional experts. Pretest was done on $6 \%$ of the sample size in four health centers found in Jimma town. Reliability test was done and chrombach's alpha coefficient was 0.84 . Modification of tools was done prior to actual data collection time based on pretest results. Data collectors were two diploma nurses and one diploma midwife who know more about the topic issue. Supervisor was one degree nurse on academic status of Graduate assistant II. Detail training was given for data collectors and supervisor. Daily, supervisor and principal investigator supervised and checked the completeness and quality of data. Incomplete and inconsistent questionnaires were excluded from analysis.

Data was coded and entered to EpiData Manager and exported to SPSS version 20 and analyzed. Each correct alternative under each knowledge questions was graded as 1point and incorrect was graded as 0 . Finally, it was dichotomized as good knowledge and poor knowledge based on the sum of correct responses by taking the mean score as cutoff point. Practice of essential newborn care was graded by assigning scores to Likert scale responses on a scale of $0-2$ points: $0=$ never, $1=$ sometimes, 2 =always. There were 24 items of practical question and the maximum total score for practice was considered to be 48 . The total score was dichotomized in to good practice and poor practice based on the summed score taking the mean score as cut-off point. Bivariate analysis was done to determine candidates for multivariate analysis. Those variables which have significant association fatherly analyzed by multivariate Logistic regression to identify the independent predictors of knowledge and practice of ENC. Confidence interval of $95 \%$ was used to see the precision of the study and the statistical association was considered as significant if $\mathrm{p}$-value is less than 0.05 .

Before starting any steps, ethical clearance and approval was obtained from the ethical committee of Addis Ababa University. Official letter was obtained from department of Nursing and brought to Oromia regional health Bureau and then written permission was provided to Jimma Zone health Office and from there to respective Districts health offices. Oral permission was ensured from each health center managers. Finally, the data collectors gave detail explanation of the purpose and possible benefit of the study, clarified that participation is voluntary, as well as respect of the subject privacy was ensured, obtained written consent of participants and confidentiality of the data was kept.

\section{Results}

\section{Socio-demographic characteristics}

From the total 279 estimated sample, five questionnaires were excluded as a result of incompleteness and inconsistencies and two questionnaires were not returned back, making the response rate of $97.49 \%$. The analysis was done based on the data collected from 272 participants. Accordingly, largest proportion of the respondents were between the ages of 25 and 29 years and smallest proportion found between 40 and 44 years. The participants age ranges from 22 to 51 years with the mean of $28.86(\mathrm{SD}= \pm 5.78)$ years. Two third and $3 / 4$ of the study participants had less than six years' experience of delivery care service. Among the study participants, 60 (22.1\%) had no interest 
Citation: Negussie BB, Hailu FB, Megenta AD (2018) Knowledge and Practice of Essential Newborn Care and Associated Factors among Nurses and Midwives Working at Health Centers in Jimma Zone, Ethiopia, 2016. J Nurs Care 7: 446. doi:10.4172/2167-1168.1000446

Page 3 of 10

to work in delivery room, $164(60.3 \%)$ had work load. Regarding availability of equipment and vaccines of newborn care, $125(46.0 \%)$ and 117 (43.0\%) of study subjects were responded that all equipment, vaccines and drugs respectively were available at their health institution. The study revealed that, only $101(37.1 \%)$ of respondents were took training on new born care (Table 1).

\begin{tabular}{|c|c|c|c|}
\hline Question & Response & Frequency & Percent \\
\hline \multirow{5}{*}{$\begin{array}{l}\text { Work experience in health care } \\
\text { services in years }\end{array}$} & $0-5$ & 180 & 66.2 \\
\hline & $6-10$ & 69 & 25.4 \\
\hline & $11-15$ & 2 & 0.7 \\
\hline & $16-20$ & 8 & 2.9 \\
\hline & $>20$ & 13 & 4.8 \\
\hline \multirow{5}{*}{$\begin{array}{l}\text { Work experience of delivery service } \\
\text { in years }\end{array}$} & $0-5$ & 208 & 76.5 \\
\hline & $6-10$ & 46 & 16.9 \\
\hline & $11-15$ & 4 & 1.5 \\
\hline & $16-20$ & 5 & 1.8 \\
\hline & $>20$ & 9 & 3.3 \\
\hline \multirow{2}{*}{ Interest to work in delivery room } & Yes & 212 & 77.9 \\
\hline & No & 60 & 22.1 \\
\hline \multirow{2}{*}{ Availability of equipment } & Yes & 125 & 46 \\
\hline & No & 147 & 54 \\
\hline \multirow[t]{2}{*}{ Availability of drugs and vaccines } & Yes & 117 & 43 \\
\hline & No & 155 & 57 \\
\hline \multirow{2}{*}{ Work load } & Yes & 164 & 60.3 \\
\hline & No & 108 & 39.7 \\
\hline \multirow{2}{*}{ In service training } & Yes & 101 & 37.1 \\
\hline & No & 171 & 62.9 \\
\hline \multirow{3}{*}{ Number of in service trainings } & One & 53 & 52.5 \\
\hline & Two & 35 & 34.7 \\
\hline & $>$ Three & 13 & 12.9 \\
\hline
\end{tabular}

Table 1: Distribution some selected factors of knowledge and practice of ENC $(n=272)$.

\section{Knowledge and Practice of Airway Management}

Regarding measures to be taken for babies not cries immediately after delivery, $205(75.4 \%)$ of them knew that the correct measure is calling a help and start resuscitation, whereas the remaining did not know. About position of the baby's head to open the airway, 169 (62.1\%) responded as head should be slightly extended and the remaining participants did not able to mention the correct position. Out of the responding participants, only 93 (34.2\%) could identify that 40 breath per minute is the recommended breath per minute during ventilation of newborn, but the left participants could not respond in line with guideline. The average knowledge score of resuscitation domain was $60.48 \%$ (Table 2).

\begin{tabular}{|c|c|c|c|}
\hline Variables & Response & Frequency & Percent \\
\hline \multirow{3}{*}{$\begin{array}{l}\text { Measures to be taken if } \\
\text { the baby not cries }\end{array}$} & $\begin{array}{l}\text { Cover the baby and allow } \\
\text { skin to skin contact }\end{array}$ & 49 & 18 \\
\hline & $\begin{array}{l}\text { Call a help and start } \\
\text { resuscitation }\end{array}$ & 205 & 75.4 \\
\hline & $\begin{array}{l}\text { Put baby on new born table } \\
\text { and give mother care }\end{array}$ & 18 & 6.6 \\
\hline \multirow{3}{*}{$\begin{array}{l}\text { Position of baby's head } \\
\text { to help open the airway }\end{array}$} & A flexed & 66 & 24.3 \\
\hline & Slightly extended & 169 & 62.1 \\
\hline & Hyper extended & 37 & 13.6 \\
\hline \multirow{2}{*}{$\begin{array}{l}\text { The mentioned } \\
\text { measures if baby is not } \\
\text { breathing well after } \\
\text { stimulation }\end{array}$} & More stimulation to breath & 81 & 29.8 \\
\hline & $\begin{array}{c}\text { Ventilation with bag and } \\
\text { mask }\end{array}$ & 191 & 70.2 \\
\hline \multirow{3}{*}{$\begin{array}{l}\text { The mentioned } \\
\text { breath } / \mathrm{min}\end{array}$} & 30 & 87 & 32 \\
\hline & 40 & 93 & 34.2 \\
\hline & 60 & 92 & 33.8 \\
\hline
\end{tabular}

Table 2: Knowledge on neonatal airway management $(n=272)$.

When the respondents asked about wiping of face and eyes, 128 (47.1\%) responded that they applied always whereas $58(21.3 \%)$ of the respondents did not apply at all. Regarding Apgar score, 168 (61.8\%) of the respondents took Apgar score of all delivery they conducted, 82 (30.1\%) took only for some babies. Concerning airway clearance, 181 (66.5\%) respondents were applied the principle of checking and sucking airway for all babies they delivered, 86 (31.6\%) were applied for some babies. Majority, 201 (73.9\%) were checked for breathing while drying it always, whereas $63(23.2 \%)$ were checked only sometimes (Table 3).

\begin{tabular}{|c|c|c|c|}
\hline Item of practice & Response & Frequency & Percent \\
\hline \multirow{3}{*}{$\begin{array}{l}\text { Wipes the eyes and face } \\
\text { when the head is delivered }\end{array}$} & No never & 58 & 21.3 \\
\hline & Yes, some times & 86 & 31.6 \\
\hline & Yes, always & 128 & 47.1 \\
\hline \multirow{3}{*}{ Taking Apgar Score } & No never & 22 & 8.1 \\
\hline & Yes, some times & 82 & 30.1 \\
\hline & Yes, always & 168 & 61.8 \\
\hline \multirow{3}{*}{$\begin{array}{l}\text { check and Sucks the air } \\
\text { way }\end{array}$} & No never & 5 & 1.8 \\
\hline & Yes, some times & 86 & 31.6 \\
\hline & Yes, always & 181 & 66.5 \\
\hline \multirow{3}{*}{$\begin{array}{c}\text { Check for breathing while } \\
\text { drying }\end{array}$} & No never & 8 & 2.9 \\
\hline & Yes, some times & 63 & 23.2 \\
\hline & Yes, always & 201 & 73.9 \\
\hline
\end{tabular}

Table 3: Practice on neonatal airway management $(n=272)$. 
Citation: Negussie BB, Hailu FB, Megenta AD (2018) Knowledge and Practice of Essential Newborn Care and Associated Factors among Nurses and Midwives Working at Health Centers in Jimma Zone, Ethiopia, 2016. J Nurs Care 7: 446. doi:10.4172/2167-1168.1000446

Page 4 of 10

\section{Knowledge and Practice of Thermal Protection}

According to the study, $183(67.3 \%)$ respondents knew that newborn should be bathed after $24 \mathrm{~h}$ of delivery, but the remaining 89 (32.7\%) of the respondents did not know the recommended time for bathing. About methods of thermal protection, 136 (50.0\%) were aware that immediately dry can be used and $204(75.0 \%)$ were aware that we can use skin to skin contact whereas $12(4.4 \%)$ responded as early bathing which is not correct method of thermal protection. Regarding newborn placement immediately after birth, majority, 210 (77.2\%) knew that newborn should kept on the mother's belly immediately after birth, but $62(22.8 \%)$ did not know (Table 4 ).

\begin{tabular}{|c|c|c|c|}
\hline \multirow{4}{*}{ Questions } & Response & Frequency & Percent \\
\hline \multirow{4}{*}{ Time of newborn bathing } & Immediately & 11 & 4 \\
\cline { 2 - 4 } & Within the first 24 h & 78 & 28.7 \\
\cline { 2 - 4 } & After 24 h of delivery & 183 & 67.3 \\
\hline \multirow{4}{*}{$\begin{array}{c}\text { Methods of thermal } \\
\text { protection }\end{array}$} & Immediately dry & 136 & 50 \\
\cline { 2 - 4 } & $\begin{array}{c}\text { Allow skin to skin } \\
\text { contact }\end{array}$ & 204 & 75 \\
\cline { 2 - 4 } & Early bathing & 12 & 4.4 \\
\hline \multirow{2}{*}{$\begin{array}{c}\text { Where newborn should kept } \\
\text { immediately after birth }\end{array}$} & Beside the mother & 26 & 9.6 \\
\cline { 2 - 4 } & With someone else & 1 & 0.4 \\
\cline { 2 - 4 } & On the mother's belly & 210 & 77.2 \\
\cline { 2 - 4 } & $\begin{array}{r}\text { On newborn bed/ } \\
\text { table }\end{array}$ & 35 & 12.9 \\
\hline
\end{tabular}

Table 4: Knowledge of thermal protection $(n=272)$.

Regarding to thermal protection, 218 (80.1\%) of the participants dried all newborn immediately after delivery with dry towel whereas $63(23.2 \%)$ applied only for some babies. Out of the total respondents, $198(72.8 \%)$ Kept all babies on mothers belly immediately after delivery whereas 7 (2.6\%) of them did not kept, 154 (56.6\%) discarded wet towel and cover with dry towel for all babies while109 (40.1\%) of them applied for some babies. Majority, 235 (86.4\%) of them initiated breast feeding within the first hours of delivery (Table 5).

\begin{tabular}{|c|c|c|c|}
\hline Questions & Response & Frequency & Percent \\
\hline \multirow{3}{*}{$\begin{array}{c}\text { Drying the baby immediately with } \\
\text { dry towel }\end{array}$} & No, never & 7 & 2.6 \\
\cline { 2 - 4 } & Yes, some times & 47 & 17.3 \\
\cline { 2 - 4 } & Yes, always & 218 & 80.1 \\
\hline \multirow{3}{*}{$\begin{array}{c}\text { Discarding wet towel and cover } \\
\text { the baby with dry towel }\end{array}$} & No, never & 9 & 3.3 \\
\cline { 2 - 4 } & Yes, some times & 109 & 40.1 \\
\cline { 2 - 4 } & Yes, always & 154 & 56.6 \\
\hline \multirow{2}{*}{$\begin{array}{c}\text { Keeping the baby on mothers bell } \\
\text { immediately after birth }\end{array}$} & Nos, never & 7 & 2.6 \\
\cline { 2 - 4 } & Yes, always & 198 & 72.8 \\
\cline { 2 - 4 } & Nome times & 67 & 24.6 \\
\hline
\end{tabular}

\begin{tabular}{|c|c|c|c|}
\hline \multirow{3}{*}{$\begin{array}{c}\text { Keeping skin to skin contact with } \\
\text { the mother }\end{array}$} & No, never & 8 & 2.9 \\
\cline { 2 - 4 } & Yes, some times & 95 & 34.9 \\
\cline { 2 - 4 } & Yes, always & 169 & 62.1 \\
\hline \multirow{3}{*}{$\begin{array}{c}\text { Initiating breast feeding Within the } \\
\text { first hour of delivery }\end{array}$} & No, never & 0 & $0.00 \%$ \\
\cline { 2 - 4 } & Yes, some times & 37 & 13.3 \\
\cline { 2 - 4 } & Yes, always & 235 & 86.4 \\
\hline
\end{tabular}

Table 5: Practice of thermal protection $(n=272)$.

\section{Knowledge of Breast Feeding}

Regarding breast feeding, 234 (86.0\%) of study participants were aware that initiation of breast feeding after delivery should be taken within the first hours of delivery, more than $3 / 4$ were aware that colostrums has infection protection role in newborn whereas the remaining $56(20.6 \%)$ did not aware. About duration of exclusive breast feeding, $210(77.2 \%)$ of the respondents knew that the mother should feed exclusively for the first six months (Table 6).

\begin{tabular}{|c|c|c|c|}
\hline Questions & Response & $\begin{array}{c}\text { Frequenc } \\
y\end{array}$ & Percent \\
\hline \multirow{3}{*}{$\begin{array}{l}\text { Initiation of breast } \\
\text { feeding }\end{array}$} & Within $1 \mathrm{~h}$ of delivery & 234 & 86 \\
\hline & Within $1-6 \mathrm{~h}$ of delivery & 34 & 12.5 \\
\hline & $>6 \mathrm{~h}$ of delivery & 4 & 1.5 \\
\hline \multirow{2}{*}{$\begin{array}{l}\text { Colostrum has infection } \\
\text { protection role }\end{array}$} & Yes & 216 & 79.4 \\
\hline & No & 56 & 20.6 \\
\hline \multirow{3}{*}{$\begin{array}{l}\text { Duration of exclusive } \\
\text { breast feeding }\end{array}$} & $<6$ months & 13 & 4.8 \\
\hline & For 6 months & 210 & 77.2 \\
\hline & $>6$ months & 49 & 18 \\
\hline
\end{tabular}

Table 6: Knowledge of breast feeding $(n=272)$.

\section{Knowledge and Practice of Prevention of Infection and Cord Care}

Regarding cord care, 103 (37.9\%) of participants were aware that the cord of crying baby should be clamped at 2-3 minutes of delivery, but $169(62.1 \%)$ did not respond correctly. About recommended care of dirty umbilical cord, 99 (36.4\%) were aware that it should be cleaned with soap and water, dried and no need of bandaging, but, $63.6 \%$ responded wrongly. About the recommended cares of low birth weight babies, 145 (53.3\%), $192(70 \%)$ and $46(16.9 \%)$ could identify that breast feeding early and frequently, keeping the child warm and infection prevention respectively are the recommended cares whereas $11(4.0 \%)$ responded as bathing often which is contradictory with WHO guidelines (Table 7). 
Citation: Negussie BB, Hailu FB, Megenta AD (2018) Knowledge and Practice of Essential Newborn Care and Associated Factors among Nurses and Midwives Working at Health Centers in Jimma Zone, Ethiopia, 2016. J Nurs Care 7: 446. doi:10.4172/2167-1168.1000446

Page 5 of 10

\begin{tabular}{|c|c|c|c|}
\hline Questions & Response & Frequency & Percent \\
\hline \multirow{3}{*}{ Time to clamp or tie the umbilical cord of a crying baby } & Immediately & 102 & 37.5 \\
\hline & $1-2 \mathrm{~min}$ & 67 & 24.6 \\
\hline & $2-3 \mathrm{~min}$ & 103 & 37.9 \\
\hline \multirow{4}{*}{ Instrument to cut the cord } & Clean Scissor & 20 & 7.4 \\
\hline & New Surgical blade & 66 & 24.3 \\
\hline & New razor blade & 6 & 2.2 \\
\hline & Sterile Scissor & 254 & 93.4 \\
\hline \multirow{4}{*}{ Care of dirty umbilical cord } & Clean with soap and water and cover with bandage & 67 & 24.6 \\
\hline & Clean it with soap and water, dry it and do not cover & 99 & 36.4 \\
\hline & Use alcohol to clean the umbilicus & 103 & 37.9. \\
\hline & Clean with sterile water and apply topical antibiotics & 3 & 1.1 \\
\hline \multirow{4}{*}{ Treatment of eye infection in newborn } & Apply nothing & 7 & 2.6 \\
\hline & Apply breast milk & 6 & 2.2 \\
\hline & Clean with sterile water & 74 & 27.2 \\
\hline & Apply silver nitrate/tetracycline & 252 & 92.6 \\
\hline \multirow{4}{*}{ Care for Low Birth Weight } & Bath often & 11 & 4 \\
\hline & Breast feeding early and frequently & 145 & 53.3 \\
\hline & Keep the child warm & 192 & 70.6 \\
\hline & Prevent infection & 46 & 16.9 \\
\hline
\end{tabular}

Table 7: Knowledge of respondents on prevention of infection and cord care $(n=272)$.

About personal protective equipment, 207 (76.1\%) used sterile glove during cord care for all babies whereas 64 (23.5\%) of them used some times only .Of the total respondents, only $51(18.8 \%)$ wore clean mask for all deliveries, $123(45.2 \%)$ of the respondents did not wear clean mask for all deliveries they conducted, 123 (45.2\%) of them wore clean apron during all deliveries they conducted whereas 45 (16.5\%) did not wear at all. Concerning hand washing during delivery, only 37 (13.6\%) reported that they always wash their hand with soap and water before procedure whereas $133(48.9 \%)$ did not wash their hand before all delivery they conducted. On the other hand, only 40 (14.7\%) study participants ensured all mother to wash their hands before handling the baby. Regarding cord care, 87 (32.0\%) waited for 2-3 min after delivery to clamp the umbilical cord of all crying babies while 126 (46.3\%) clamped the cord of all crying babies within less than 2 min or immediately after baby delivered. After clamping the cord, the vast majority, 250 (91.9\%) were used sterile scissor to cut the cord but, 22 (8.1\%) were used sterile scissor sometimes only. Of the study participants, 118 (43.4\%) reported that they gave cord care by cleaning and letting it to air dry whereas $113(41.5 \%)$ of them applied this care only for some babies they delivered.

On eye care, more than half did not clean eyes immediately after birth whereas $85(31.3 \%)$ were applied this care only sometimes, but few, $28(10.3 \%)$ of them reported that they applied this care for all babies they delivered. Of the total participants, 149 (54.8\%) were reported that they applied eye ointment for all newborns they delivered, 107 (39.3\%) were applied sometimes. When they apply eye ointment, 178 (65.4\%) applied without touching the eyes with the tip of ampule but $34(12.5 \%)$ applied always by touching. More than three quarters of the participants reported that they weighed and recorded the weight of all babies they delivered (Table 8).

\begin{tabular}{|l|l|l|l|}
\hline \multirow{2}{*}{ Item of practice } & \multicolumn{2}{l|}{ Level of practice } \\
\cline { 2 - 4 } & No, never & $\begin{array}{l}\text { Yes, some } \\
\text { times }\end{array}$ & Yes, always \\
\hline Put on sterile glove & $1(0.4 \%)$ & $64(23.5 \%)$ & $207(76.1 \%)$ \\
\hline Wearing mask & $123(45.2 \%)$ & $98(36.0 \%)$ & $51(18.8 \%)$ \\
\hline Wearing apron & $45(16.5 \%)$ & $104(38.2 \%)$ & $123(45.2 \%)$ \\
\hline $\begin{array}{l}\text { Hand washing before the } \\
\text { procedure }\end{array}$ & $133(48.9 \%)$ & $102(37.5 \%)$ & $37(13.6 \%)$ \\
\hline $\begin{array}{l}\text { clean eyes immediately after } \\
\text { birth from medial to lateral side } \\
\text { with swab soaked in sterile } \\
\text { water }\end{array}$ & $159(58.5 \%)$ & $85(31.3 \%)$ & $28(10.3 \%)$ \\
\hline \begin{tabular}{l} 
Using Sterile Scissor \\
\hline$y y y$
\end{tabular} & $0(0 \%)$ & $22(8.1 \%)$ & $250(91.9 \%)$ \\
\hline
\end{tabular}


Citation: Negussie BB, Hailu FB, Megenta AD (2018) Knowledge and Practice of Essential Newborn Care and Associated Factors among Nurses and Midwives Working at Health Centers in Jimma Zone, Ethiopia, 2016. J Nurs Care 7: 446. doi:10.4172/2167-1168.1000446

Page 6 of 10

\begin{tabular}{|l|l|l|l|}
\hline $\begin{array}{l}\text { Clamping the cord within 2-3 } \\
\text { min }\end{array}$ & $126(46.3 \%)$ & $59(21.7 \%)$ & $87(32.0 \%)$ \\
\hline $\begin{array}{l}\text { Ensuring the mother wash her } \\
\text { hands }\end{array}$ & $145(53.3 \%)$ & $87(32.0 \%)$ & $40(14.7 \%)$ \\
\hline Giving eye ointment & $16(5.9 \%)$ & $107(39.3 \%)$ & $149(54.8 \%)$ \\
\hline $\begin{array}{l}\text { Not touching the eyes with the } \\
\text { tip of the ampule }\end{array}$ & $34(12.5 \%)$ & $60(22.1 \%)$ & $178(65.4 \%)$ \\
\hline $\begin{array}{l}\text { Cleaning the cord and letting to } \\
\text { air dry }\end{array}$ & $41(15.1 \%)$ & $113(41.5 \%)$ & $118(43.4 \%)$ \\
\hline $\begin{array}{l}\text { Weigh and record the baby's } \\
\text { weight }\end{array}$ & $2(0.7 \%)$ & $32(11.8 \%)$ & $238(87.5 \%)$ \\
\hline
\end{tabular}

Table 8: Practice of infection prevention and cord care $(n=272)$.

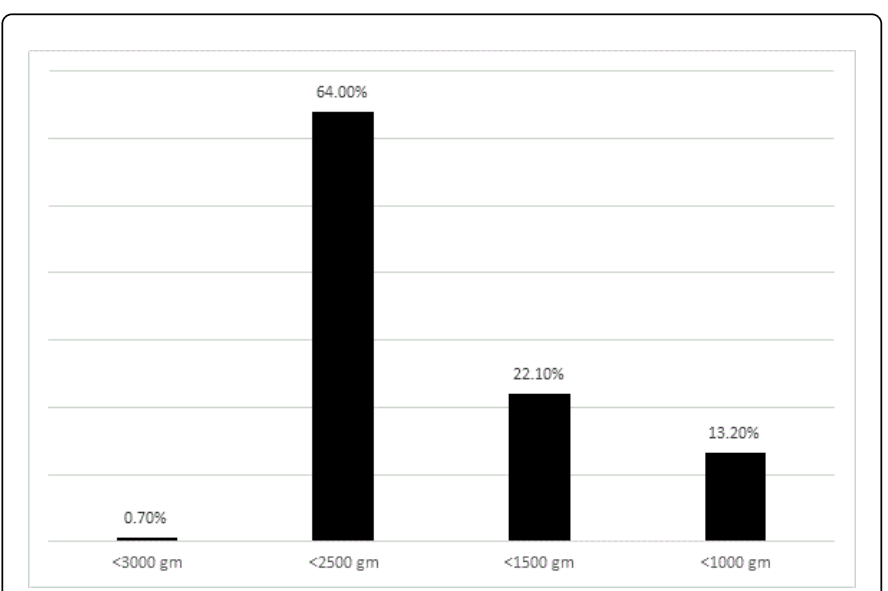

Figure 1: Knowledge of low birth weight $(n=272)$.

As shown in Figure 1 above, nearly two third (64.0\%) knew that low birth weight is weight less than $2500 \mathrm{~g}$ but, 60 (22.1\%) defined as weight of less than $1500 \mathrm{~g}, 36(13.2 \%)$ of them defined as less than 1000 and $2(0.7 \%)$ defined as weight of less than $3000 \mathrm{~g}$.

According to the study, 104 (38.2\%) of the study participants were aware that immediate newborn care should start just during birth whereas $28(10.3 \%)$ and $138(50.7 \%)$ responded as it should start before birth and after birth respectively and $2(0.7 \%)$ of them responded as they do not know when it should start. The vast majority $(90.1 \%)$ of the participants were aware that bleeding in newborn can be prevented by giving Vitamin K and the remaining 27 (9.9\%) did not know the correct action to prevent. Regarding time of postnatal visit, $214(78.7 \%)$ was aware that the best time of first post natal visit should be within the first $24 \mathrm{~h}$ of delivery (Table 9 ).

\begin{tabular}{|l|l|l|l|}
\hline Variables & Response & Frequency & Percent \\
\hline \multirow{2}{*}{ Time for first postnatal visit } & Within the first 24 h & 214 & 78.7 \\
\cline { 2 - 4 } & On the 3rd day & 46 & 16.9 \\
\cline { 2 - 4 } & On the 7th day & 12 & 4.4 \\
\hline \multirow{2}{*}{$\begin{array}{c}\text { Mentioned vaccines as } \\
\text { components ENC }\end{array}$} & BCG & 237 & 87.1 \\
\cline { 2 - 4 } & OPV & 261 & 96 \\
\hline
\end{tabular}

\begin{tabular}{|c|c|c|c|}
\hline & TTC & 49 & 18 \\
\hline & Vit k & 94 & 34.6 \\
\hline & Rota & 2 & 0.74 \\
\hline & PCV & 2 & 0.74 \\
\hline & Pentavalent & 1 & 0.37 \\
\hline \multirow{3}{*}{$\begin{array}{l}\text { Action to prevent bleeding } \\
\text { in newborn }\end{array}$} & Breastfeeding & 12 & 4.4 \\
\hline & $\begin{array}{l}\text { Not necessary to give } \\
\text { anything }\end{array}$ & 15 & 5.5 \\
\hline & Give vitamin $\mathrm{K}$ & 245 & 90.1 \\
\hline \multirow{3}{*}{$\begin{array}{l}\text { Dose of Vitamin } \mathrm{k} \text { for } \\
\text { preterm babies }\end{array}$} & $1 \mathrm{mg}$ & 107 & 39.3 \\
\hline & $0.5 \mathrm{mg}$ & 160 & 58.8 \\
\hline & Other dose & 5 & 1.8 \\
\hline
\end{tabular}

Table 9: Knowledge of some components of post natal care and bleeding prevention in new born $(\mathrm{n}=272)$.

\section{Knowledge of Newborn Danger Signs}

Respondents were considered as knowledgeable if they could identify at least four out the common 11 dager signs. Accordingly, less than $1 / 3$ could mention four and more newborn danger signs whereas more than $2 / 3$ could identify only three and less than three .The only two danger signs those more than half of respondents, $162(59.6 \%)$ and $139(51.1 \%)$ of them could mention were poor suckling and difficulty breathing respectively. To lesser extent, respondents were also able to mention fever 99 (36.4\%), yellow palms/sole/eyes 77 (28.3\%), lethargy 70 (25.7\%), convulsion 51 (18.8\%), baby too small/ born too early 44 $(16.2 \%)$, redness/discharge at the cord $32(11.8 \%)$ and the remaining respondents could list few danger signs; eyes red/swollen/discharge 26 (9.6\%), baby feels cold 19 (7.0\%), loss of consciousness 13 (4.8\%).

The overall mean knowledge score of study participants was 23.27 $(\mathrm{SD}= \pm 4.39)$ out of the total 35 points which revealed that $52.2 \%$ of the respondents had good knowledge of ENC where as $47.8 \%$ had poor knowledge. The mean score of practice of ENC was $32.82(\mathrm{SD}= \pm 7.35)$ out of the total 48 points. An overall practice of ENC, $51.1 \%$ of the respondents had good level of practice and the remaining $48.9 \%$ of them had poor level of practice.

\section{Some Factors of Knowledge and Practice of Essential Newborn Care}

A cording to the study, Age, Religion, Ethnicity, marital status, work experience and work load were not found to have significant association with participants' level of knowledge of ENC. Field of study was significantly associated with participants' knowledge about ENC care $(\mathrm{p}=0.001)$. Midwives were 3.899 times more likely knowledgeable than nurses (AOR (95\% CI) 3.899 (1.781-8.537)). Educational qualification was also found to have association $(\mathrm{p}<0.001)$.Diploma holders were 0.250 times less likely knowledgeable about ENC than degree holders (AOR (95\% CI) $0.250(0.120-0.523)$ ). Interest to work in delivery room was statistically significant $(\mathrm{p}=0.005)$. Those who had interest to work in delivery room were 2.822 times more likely knowledgeable than who had no interest (AOR (95\% CI) 2.822 (1.372-5.807)). Training Also found to be a factor for knowledge of 
Citation: Negussie BB, Hailu FB, Megenta AD (2018) Knowledge and Practice of Essential Newborn Care and Associated Factors among Nurses and Midwives Working at Health Centers in Jimma Zone, Ethiopia, 2016. J Nurs Care 7: 446. doi:10.4172/2167-1168.1000446

Page 7 of 10

ENC $(p<0.001)$. Those participants who had at least one in-service training were 3.421 more likely knowledgeable than those did not trained at all (AOR (95\%) 3.421 (1.779-6.579)) (Table 10).

\begin{tabular}{|c|c|c|c|c|c|c|}
\hline Variables & Good knowledge & Poor knowledge & $\operatorname{COR}(95 \% \mathrm{Cl})$ & $P$ value & AOR(95\% Cl) & $P$ values \\
\hline \multicolumn{7}{|l|}{ Sex } \\
\hline Female & $81(57.0 \%)$ & $51(39.2 \%)$ & \multirow[b]{2}{*}{$0.486(0.300-0.780)$} & \multirow[b]{2}{*}{$0.004^{*}$} & \multirow[b]{2}{*}{$1.008(0.544-11.868)$} & \multirow[b]{2}{*}{0.979} \\
\hline Male & $61(43.0 \%)$ & $79(60.8 \%)$ & & & & \\
\hline \multicolumn{7}{|l|}{ Field } \\
\hline Nursing & $76(53.5 \%$ & $115(88.5 \%$ & \multirow[b]{2}{*}{$6.658(3.542-12.514)$} & \multirow[b]{2}{*}{$<0.001$} & \multirow[b]{2}{*}{$3.899(1.781-8.537)$} & \multirow[b]{2}{*}{$0.001^{*}$} \\
\hline Midwifery & $66(46.5 \%)$ & $15(11.5 \%)$ & & & & \\
\hline \multicolumn{7}{|c|}{ Qualification } \\
\hline Degree & $34(23.9 \%)$ & $16(12.3 \%)$ & \multirow[b]{2}{*}{$0.446(0.233-0.854)$} & \multirow[b]{2}{*}{$0.015^{*}$} & \multirow[b]{2}{*}{$0.250(0.120-0.523)$} & \multirow[b]{2}{*}{$<0.001^{*}$} \\
\hline Diploma & $108(76.1 \%)$ & $114(87.7 \%)$ & & & & \\
\hline \multicolumn{7}{|l|}{ Interest } \\
\hline No & $15(10.6 \%)$ & $45(34.6 \%)$ & \multirow[b]{2}{*}{$4.482(2.350-8.549)$} & \multirow[b]{2}{*}{$<0.001^{*}$} & \multirow[b]{2}{*}{$2.822(1.372-5.807)$} & \multirow[b]{2}{*}{$0.005^{*}$} \\
\hline Yes & $127(89.4 \%)$ & $85(65.4 \%)$ & & & & \\
\hline \multicolumn{7}{|l|}{ Training } \\
\hline No & $64(45.1 \%)$ & $107(82.3 \%)$ & \multirow[b]{2}{*}{$5.67(3.243-9.914)$} & \multirow[b]{2}{*}{$<0.001^{*}$} & \multirow[b]{2}{*}{$3.421(1.779-6.579)$} & \multirow[b]{2}{*}{$<0.001^{*}$} \\
\hline Yes & $78(54.9 \%)$ & $23(17.7 \%)$ & & & & \\
\hline
\end{tabular}

Table 10: Association of socio-demographic characteristics and some selected variables.

Age, Religion, Ethnicity, marital status, work experience, work load and monthly salary were statistically insignificant with practice of ENC. Field of study was found to have significant association with their practice of ENC $(\mathrm{p}<0.001)$. Midwives were 4.419 times more likely practiced essential newborn care than nurses but, the association was insignificant after adjusting for possible confounder. Educational qualification was also found to have significant association with participants' practice of ENC ( $\mathrm{p}=0.003$ ). Diploma holders were 0.287 times less likely practiced than degree holders (AOR (95\% CI) 0.287 (0.126-0.650)). Interest of participant to work in delivery room was found to be a factor for practice of ENC ( $p=0.008)$. Those who had interest to work in delivery room were 3.006 times more likely practiced than who had no interest (AOR (95\% CI) 3.006 $(1.328-6.804))$.
There was significant difference between those who trained and not trained $(\mathrm{p}=0.004)$. Participants who had at least one time training on ENC were 2.937 more likely practiced than those did not trained (AOR (95\% CI) 2.937 (1.415-6.098)). On bivariate analysis, availability of newborn care equipment at health centers and newborn care drugs and vaccines were found to have association with ENC practice $(\mathrm{p}=0.002)$ and $(\mathrm{p}=0.001)$, respectively but after adjustment of possible confounders, both variables were statistically insignificant. The study also showed significant association between level of knowledge and level of practice of ENC $(\mathrm{p}<0.001)$. Those respondents who had good knowledge were 4.848 times more likely practiced than those who had poor knowledge ((AOR (95\% CI) 4.848 (2.605-9.023)) (Table 11).

\begin{tabular}{|l|l|l|l|l|l|l|l|}
\hline Variable & Poor practice & Good practice & COR(95\% Cl) & P-Value & AOR (95\%Cl) & P-value \\
\hline Sex & $54(40.6 \%)$ & $78(56.1 \%)$ & $0.535(0.330-0.865)$ & 0.011 & $1.025(0.527-1.991)$ \\
\hline Female & $79(59.4 \%)$ & $61(43.9 \%)$ & & & & 0.943 \\
\hline Male & $113(85.0 \%)$ & $78(56.1 \%)$ & $4.419(2.470-7.905)$ & $<0.001$ & $1.522(0.667-3.472)$ \\
\hline Field & $20(15.0 \%)$ & $61(43.9 \%)$ & & & & 0.319 \\
\hline Nursing & & & \\
\hline
\end{tabular}


Citation: Negussie BB, Hailu FB, Megenta AD (2018) Knowledge and Practice of Essential Newborn Care and Associated Factors among Nurses and Midwives Working at Health Centers in Jimma Zone, Ethiopia, 2016. J Nurs Care 7: 446. doi:10.4172/2167-1168.1000446

Page 8 of 10

\begin{tabular}{|c|c|c|c|c|c|c|}
\hline \multicolumn{7}{|c|}{ Qualification } \\
\hline Degree & $14(10.5 \%)$ & $36(25.9 \%)$ & $0.337(0.172-0.659)$ & 0.001 & $0.297(0.126-0.650)$ & 0.003 \\
\hline Diploma & $119(89.5 \%)$ & $103(74.1 \%)$ & & & & \\
\hline \multicolumn{7}{|l|}{ Interest } \\
\hline No & $47(35.3 \%)$ & $13(9.4 \%)$ & $5.297(2.703-10.378)$ & $<0.001$ & $3.006(1.328-6.804)$ & 0.008 \\
\hline Yes & $86(64.7 \%)$ & $126(90.6 \%)$ & & & & \\
\hline \multicolumn{7}{|l|}{ Training } \\
\hline No & $108(81.2 \%)$ & $63(45.3 \%)$ & $5.211(3.012-9.018)$ & $<0.001$ & $2.937(1.415-6.098)$ & 0.004 \\
\hline Yes & $25(18.8 \%)$ & $76(54.7 \%)$ & & & & \\
\hline \multicolumn{7}{|c|}{ Availability of equipment } \\
\hline No & $85(63.9 \%)$ & $62(44.6 \%)$ & $2.199(1.352-3.579)$ & 0.002 & $0.964(0.485-1.139)$ & 0.916 \\
\hline Yes & $48(36.1 \%)$ & $77(55.4 \%)$ & & & & \\
\hline \multicolumn{7}{|c|}{ Availability of drugs and vaccine } \\
\hline No & $90(67.7 \%)$ & $65(46.8 \%)$ & $2.383(1.455-3.901)$ & 0.001 & $1.687(0.861-3.307)$ & 0.128 \\
\hline Yes & $43(32.3 \%)$ & $74(53.2 \%)$ & & & & \\
\hline \multicolumn{7}{|c|}{ Knowledge } \\
\hline Poor & $98(73.7 \%)$ & $32(23.0 \%)$ & $9.362(5.390-16.263)$ & $<0.001$ & $4.848(2.605-9.023)$ & $<0.001$ \\
\hline Good & $35(26.3 \%)$ & $107(77.0 \%)$ & & & & \\
\hline
\end{tabular}

Table 11: Association of selected socio-demographic variables, personal and institutional factors with practice of essential new born care.

\section{Discussion}

Knowledge is one of the crucial aspects of health systems for ENC practices and lack of knowledge may impede provision of ENC. In this study, the average knowledge and practice score about ENC were $66.48 \%$ and $68.38 \%$, respectively. This is lower compared to study conducted in India [16,17]. The discrepancy could be due to the difference in in-service training. But this knowledge is higher than that of Khartoum [1], Tanzania [13] and Ethiopia [15]. In this study, 52.2\% of the respondents had good knowledge and $47.8 \%$ had poor knowledge whereas, $51.1 \%$ had good and $48.9 \%$ had poor level of practice. This is relatively higher compared to Egypt [18], Uganda [19] and India [16]. This discrepancy in level of practice could be due to methodological difference. The slight difference in knowledge might be due to difference between study participants in which only nurses participated in case of study conducted in Egypt and it included nurse assistants in case of Uganda.

The study finding revealed that average knowledge score of resuscitation domain was lower compared to that of India [18] and Afghanistan [20].This difference might be due to difference in inservice training on resuscitation. Lack of knowledge can impede practice of resuscitation and increase risk of death and complication of asphyxia.

Exclusive breastfeeding has a significant protective effect against infections. Early breastfeeding and keeping the baby close to the mother reduce the risk of hypothermia and hypoglycemia and delaying of breast feeding after delivery limits the opportunities for mothers and infants to benefit from early initiation. In this study, $86.0 \%$ of participants were aware the time of breast feeding initiation and $77.2 \%$ knew duration exclusive breast feeding whereas greater than $86.4 \%$ of participants initiated feeding within one hours of delivery. This is far greater compared with study conducted in Ethiopia, Tanzania [21] and MAISHA [22]. This discrepancy could be due to the difference between study settings. Hospitals with the heaviest volume of deliveries make the providers busy to consider all components of care on time and there is also time gap between the studies; now a day government focused on newborn care and giving training for midwives. This indicated that this study increased the opportunities for mothers and infants to benefit from early initiation of breastfeeding.

Thermal protection in newborn is very important. Because, it can prevent the complication of hypothermia. According to this study, $67.3 \%$ respondents knew time of newborn bathing, $77.2 \%$ knew where newborn should kept immediately after birth, greater than $72.8 \%$ kept the baby on the mother's chest/belly, more than $80.1 \%$ dried the babies immediately with dry towel, more than $56.6 \%$ discarded wet towel and covered with dry clothes, greater than $62.1 \%$ kept the baby skin to skin contact with the mother. This is consistent with study done in Khartoum [1]. But, this study is relatively lower compared to that of Tanzania [9]. This difference might be knowledge difference between the two study group on importance of thermal protection and scarcity of newborn care equipment. On the other hand study in India revealed that, although $89 \%$ of the providers demonstrated wiping of newborn with dry cloth, $63 \%$ showed putting neonate on warm surface [17] and study in Philippine revealed that more than $90 \%$ of infants were dried 
[23]. The reason of this difference might be difference of educational level of study participants leads to knowledge difference. On the other hand the study finding is higher compared to study done in Ethiopia [15] and in other study in 4 regions of Ethiopia [13]. This difference might be time gap between these studies. Now a day government focused on newborn health and giving training and others may share experience from those trained to some extent. This study was far greater compared to that of Tanzania ;skin to skin contact occurred infrequently at health centers likely due in part to the traditional practice of keeping the infant separated from the mother [21].

Clean cord care is very important in preventing early neonatal infections. The precise timing of clamping and cutting the umbilical cord is important as there is some evidence of potential benefits for the baby when the cord is not clamped and cut immediately after birth [24]. This study finding showed that, only $37.9 \%$ of the study participants knew the precise time of cord clamping and $32.0 \%$ and $21.7 \%$ of the participants delayed clamping of umbilical cord for all babies and some babies they delivered respectively. This is lower compared to that of Tanzania [9]. The possible reason might be awareness difference on the importance of delayed cord clamping. But this study was consistence with that of Khartoum [1] and Ethiopia [15] and lower compared to that of Peru [25]. This great difference is as the reason of training in the case of Peru and it was post intervention result. The study revealed that, $13.6 \%$ washed their hand before all deliveries they conducted but $48.9 \%$ did not washed at all. The study finding also revealed that less than half consistently wore protective clothing other than gloves. This was lower than that of Tanzania [21]. The possible reason might be inadequate water and equipment of newborn care in the study institution. This study showed that, only $54.8 \%$ administered eye ointment for all babies they delivered, 39.3\% did it only for some babies, $16.9 \%$ administered vitamin $\mathrm{k}$ for all babies they delivered, $59.9 \%$ administered only for some babies whereas $23.2 \%$ did not administered at all. This is consistent when compared with results of studies conducted in Egypt [18], lower than that of Philippine [21] but higher compared to that of Uganda [19]. This supports the above difference on administration of Vitamin $\mathrm{K}$ and eye ointment might be due to difference in availability of drugs in the study area in that of Philippine rather than knowledge gap.

Knowledge of study participants on newborn danger signs is very crucial for the survival and future well-being of the babies. But this study revealed that, less than one third could mention four and more newborn danger signs. This may impede the care they can give for the child with health problems and advice they can give for the mother.

Many factors can influence knowledge and practice of ENC. In this study, in-service training, field of study, educational qualification and interest to work in delivery room were found to be factor of knowledge level and difference in year of experience was insignificant with knowledge level which is similar with that of Uganda in which there was no statistical difference in knowledge by experience and there was difference in knowledge level based on field and level of education [19]. Similarly study in Egypt revealed that, there was a significance relationship between nurses education and their knowledge, while a negative correlation were found regarding to their years of experience [18]. On the other hand, this study showed that, educational level, interest to work in delivery room, in-service training was significantly associated with level of ENC practice. This in part due to all of these factors can increase knowledge level which can lead to increment of level of practice. Compared to that of Egypt [18], no significance difference between nurses' knowledge and practices and the possible reason might be difference of study participants.

\section{Conclusion}

Despite participants had good knowledge and practice in general, they had poor knowledge and practice on some components of ENC:

The study population had knowledge gap on resuscitation domains, poor infection prevention practice and, consistently administration of Vitamin $\mathrm{K}$ and eye ointment was relatively low, poor knowledge and practice on precise cord clamping time which may leads to neonatal anemia, majority were not knowledgeable on identification of neonatal danger signs.

Majority of the study population had good practice on timely initiating of breast feeding and good knowledge and practice on thermal protection. Field of study, educational level, interest to work in delivery room and in-service training were independent predictors of knowledge. Level of education, interest to work in delivery room, inservice training and level of knowledge were found to be independent predictors of ENC practice.

\section{Recommendations}

Strengthen in-service training given to nurses and midwives on ENC including newborn resuscitation and upgrade their educational level. Give Priority for those who trained on area and for those have better educational level on the assignment of staffs working in delivery room by considering interest of staff to work in delivery room for better services, motivation should be there for those have good performance. Conduct further observational study on quality and level of ENC practice. Provide all necessary equipment, vaccine and drugs of newborn care and it is better if ministry of education incorporate all components of ENC in the curriculum for both diploma and degree program.

\section{Acknowledgement}

First of all, we would like to thank our almighty God for giving us strength and peace. Next and for most, we would like to thank Mr. Fikadu Balcha and Mr. Asrat Demissie for their unreserved and repeated constructive and valuable comments starting from the development of the proposal throughout this research report. We would like to express our heartfelt gratitude to Addis Ababa University that provided us financial support. We would also like to acknowledge Jimma zone health office, each district's health office, each health center's managers and each participants for their support and cooperation in providing us data and the necessary information .We do not want to wrap up without thanking Mr.Temamen Tesfaye and Mr.Sena Belina for their support during the evaluation of study tools and contribution of constructive ideas on analysis.

\section{References}

1. Nasor Taha FA (2013) Assessment of knowledge, attitude and practices of nurse midwives towards immediate care of the newborn in Khartoum state teaching hospitals 2011. J Am Sci 9: 263-270.

2. Paul Vinod AD (2014) Newborn nursing for facility based care. Learn Guide.

3. (2014) Every newborn: A draft action plan to end preventable deaths.

4. Saaka M, Iddrisu M (2014) Patterns and determinants of essential newborn care practices in rural areas of northern Ghana. Int J Popul Res. 
Citation: Negussie BB, Hailu FB, Megenta AD (2018) Knowledge and Practice of Essential Newborn Care and Associated Factors among Nurses and Midwives Working at Health Centers in Jimma Zone, Ethiopia, 2016. J Nurs Care 7: 446. doi:10.4172/2167-1168.1000446

Page 10 of 10

5. Narayanan I, Rose M, Cordero D, Faillace S, Sanghvi T (2004) The components of essential newborn care. Published by the basics support for institutionalizing child survival project (BASICS II) for the United States agency for international development. Arlington, Virginia.

6. Silvestre AM (2014) Early essential newborn care: Clinical practice pocket guide, World Health Organization. Regional Office for the Western Pacific.

7. Worku B, Gessesse M (2012) Newborn care training manual, essential new born care for every baby. Federal Ministry of Health Ethiopia EPS.

8. Federal Ministry of Health (2011) Saving newborn lives in Nigeria: Newborn health in the context of the Integrated Maternal, Newborn and Child Health Strategy. Abuja: Federal Ministry of Health, Save the Children, Jhpiego.

9. Makene CL, Plotkin M, Currie S, Bishanga D, Ugwi P, et al. (2014) Improvements in newborn care and newborn resuscitation following quality improvement program at scale: Results from a before and after study in Tanzania. BMC Pregnancy Childbirth 14: 1-11.

10. Federal Democratic Republic of Ethiopian Ministry of Health (2011) Integrated management of newborn and childhood illness, Part 1 Blended learning module for the health extension programed.

11. Central Statistical Agency [Ethiopia] and ICF International (2012) Ethiopia demographic and health survey 2011. Addis Ababa, Ethiopia and Calverton, Maryland, USA: Central Statistical Agency and ICF International.

12. Debelew GT, Afework MF, Yalew AW (2014) Determinants and causes of neonatal mortality in Jimma zone, southwest Ethiopia: A multilevel analysis of prospective follow up study. PLoS One 9: e107184.

13. Koru C (2013) Newborn care practices at home and in health facilities in 4 regions of Ethiopia. BMC Pediatr 13:198.

14. Lerberghe WV, Manuel A, Matthews Z and Wolfheim C (2005) Make every mother and child count. The World Health Report.

15. Ricca J, Rawlins B (2011) Quality of care for prevention and management of common maternal and newborn complications $\nabla$ : A study of Ethiopia's Hospitals 34-35.
16. Malhotra S, Zodpey SP, Vidyasagaran AL, Sharma K, Raj SS, et al. (2014) Assessment of essential newborn care services in secondary-level Facilities from two districts of India. J Health Popul Nutr 32: 130-141.

17. Van Wagner V, Epoo B, Nastapoka J, Harney E (2007) Reclaiming birth, health and community: Midwifery in the Inuit villages of Nunavik, Canada. J Midwifery Womens Health 52: 384-391.

18. Fattah E, Zein NA, Dein E (2012) Assessment of quality of nursing care provided immediately after birth at university hospital. Life Sci J 9: 2115-2126.

19. Ayiasi RM, Criel B, Orach CG, Nabiwemba E, Kolsteren P (2014) Primary healthcare worker knowledge related to prenatal and immediate newborn care: A cross sectional study in Masindi, Uganda. BMC Health Serv Res 14: 1-11.

20. Kim YM, Ansari N, Kols A, Tappis H, Currie S, et al. (2013) Assessing the capacity for newborn resuscitation and factors associated with providers' knowledge and skills: A cross-sectional study in Afghanistan. BMC Pediatr 13: 140.

21. Plotkin M, Tibaijuka G, Makene CH L, Currie SH LM (2010) Quality of care for prevention and management of common maternal and newborn complications: A study of 12 regions in Tanzania. Report 2: Findings on labour, delivery and newborn care.

22. MAISHA program (2012) MAISHA Quality of maternal and newborn care study. Key findings: immediate essential newborn care and resuscitation. Tanzania.

23. Sobel HL, Silvestre MAA, Blas J, Iii VM, Oliveros YE, et al. (2011) Immediate newborn care practices delay thermoregulation and breastfeeding initiation. Acta Paediatr 100: 1127-1133.

24. Bashir I, Migiro S (2004) National guidelines for quality obstetrics and perinatal care. Republik of Kenya.

25. Blouin B, Penny ME, Casapia M, Aguilar E, Silva H, et al. (2011) Effect of a two-component intervention to change hospital practice from early to delayed umbilical cord clamping in the Peruvian Amazon. Pan Am J Public Health 29: 322-328. 